\title{
Promovendo a aprendizagem através das redes sociais apoiada por um modelo de combinação social
}

Promoting learning through social networks supported by a model of social combination

Soraia Pacheco de A. S. Felicio HCTE/UFRJ

Universidade Federal do Rio de Janeiro soraiapas@gmail.com

\author{
Carlo E. T. Oliveira \\ Instituto Tércio Pacitti de Aplicações e \\ Pesquisas Computacionais \\ Universidade Federal do Rio de Janeiro \\ cetoli@gmail.com
}

\author{
Claudia L.R. Motta \\ Instituto Tércio Pacitti de Aplicações e \\ Pesquisas Computacionais \\ Universidade Federal do Rio de Janeiro \\ claudiam@nce.ufrj.br
}

\begin{abstract}
Resumo A busca por conhecimento aumenta cada vez mais na internet através das redes sociais. Encontrar os pares com diferentes niveis de conhecimento não é uma tarefa trivial. Propõe-se o modelo Oraculous ${ }^{1}$ baseado em estratégias de Sistemas de Combinação Social, descrevendo funcionalidades a serem integradas em um ambiente computacional para o encontro de pares. Esse modelo usa anotações que um indivíduo faz sobre páginas da Internet para modelar a combinação entre indivíduos, de modo a potencializar o aprendizado em rede através do encontro de pessoas com os mesmos interesses.
\end{abstract}

Palavras-Chave: Sistema de Combinação Social, Redes Sociais, Ambiente Virtual, Redes de Aprendizagem

\begin{abstract}
The search for knowledge is increasingly exploited in the virtual environment through social networks. Find the pairs with different levels of knowledge is not a trivial task. This work proposes the Oraculous model based on strategies of Social Matching Systems. The matching algorithm integrates into a computational environment offering relevant peer information. This model uses annotations that an individual makes on webpages to model the combination of individuals, in order to maximize the learning network through meeting people with the same interests.
\end{abstract}

Keywords: Systems Social Matching, social network, virtual environments, learning network

\footnotetext{
${ }^{1} \mathrm{O}$ significado relacionado ao artigo é "Pessoa ou entidade cujas palavras são muito respeitadas". Para Volker [20]: "Os instrumentos com os quais Apolo trabalha possivelmente indicam o que vem a ser o oráculo: textos poéticos, de realidade e alcance imediatos." . Neste contexto, Oraculous é um mecanismo que auxilia a encontrar pessoas com os mesmos interesses, através da combinação social. Essas pessoas postam textos em redes sociais. Tais textos podem ter um alcance imediato com uso desses mecanismo.
} 


\section{Introdução}

As redes sociais criadas na internet envolvem cada vez mais pessoas no mundo, segundo o IBOPE [21]. No Brasil a participação está cada vez mais acentuada, segundo dados do IBOPE [22]. Associado a este crescimento verificamos o aumento da utilização e da colaboração em espaços virtuais, fomentando a criação de mecanismos para aprimorar a interação social, em particular construir conhecimento.

O sistema de combinação social é uma nova denominação para um assunto antigo, recomendação de pessoas, que é atualmente, explorada por alguns pesquisadores para organizar as pessoas por seus interesses, em que a partir do encontro de pessoas com interesses similares, através de várias motivações seja para aprender, ensinar, construir grupos de especialistas e outros, como aponta Terveen e McDonnald [8]. O potencial dessa área é um meio de promover o compartilhamento de informações e conhecimentos através da Internet de modo mais direcionado. Esse potencial ainda é pouco explorado em ambientes virtuais. Essa é a principal motivação desse trabalho.

Neste contexto propomos um mecanismo que auxilie a identificação de pares ou de especialistas em um determinado assunto, para agilizar a aquisição de conhecimento. Um sistema de combinação social, cujo objetivo principal é a identificação de perfis similares, com determinados parâmetros pré-estabelecidos, tais como: quantidade de informações a ser apresentada, se o interesse é recente ou não, e o grau de similaridade. O sistema retorna um conjunto de pessoas recomendadas e seus artefatos postados. Tais pessoas com seus respectivos artefatos servirão de modelo para o aprendizado do indivíduo, através da observação de como se deu a curva de aprendizado construída por cada uma dessas pessoas.

$\mathrm{O}$ encontro desses pares em ambientes já existentes traz a possibilidade de aprender, através da observação de interesses de outros indivíduos disponíveis nas redes sociais. Estas redes são exemplos de espaços que podem fazer uso desse serviço como o Delicious, que possuem o serviço de Social Bookmark ${ }^{1}$, dão ao internauta condições de anotar sites como favoritos, para consultas futuras e ainda possibilitam o compartilhamento dessas anotações com outros usuários, bem como, a organização desta informação - folksonomia [25][26]. Assim, ao observar o que as pessoas estão postando nesses espaços

\footnotetext{
${ }^{1}$ Social Bookmark é um serviço oferecido por alguns sites que tem como finalidade guardar e organizar os favoritos das pessoas, para facilitar o acesso aos links e compartilhar com outros usuários que fazem uso deste tipo de serviço. Atualmente, o mais popular site que oferece esse serviço é o Delicious. [3]
}

virtuais, o indivíduo pode aprender sobre aspectos de seu interesse e de outros relacionados. Se nestes ambientes existirem formas de encontrar pessoas com os mesmos interesses, o indivíduo poderá ter um ganho maior em seu aprendizado. Notamos que a Internet possui grande potencial no uso de informações já armazenadas sobre os interesses das pessoas.

Acreditamos que o comportamento do indivíduo para adquirir conhecimento está vinculado às teorias de aprendizagem. No presente trabalho se destaca as teorias de Vygostky, com ZDP (Zona de Desenvolvimento Proximal) [9], Bandura com Aprendizagem Vicariante[1], Kelly com Psicologia dos Construtor Pessoais [4]. A ZDP explica o ganho cognitivo ao interagir com outro com um nível de conhecimento superior. O mecanismo de combinação social auxilia o encontro de pares que podem desempenhar esse papel. A Aprendizagem Vicariante explica a aprendizagem por observação. $\mathrm{O}$ indivíduo pode aprender ao observar os pares e os seus artefatos postados em um ambiente virtual. Por fim, a Psicologia dos Construtos Pessoais evidencia a importância dentro do contexto cognitivo de calcular o grau de similaridade entre o indivíduo avaliado e seus pares, através do Corolário da Construção ou Interpretação e Comunalidade, explicado com mais detalhes na Seção 2.2.

O modelo proposto realiza esse cálculo de similaridade entre o indivíduo avaliado e os seus pares, que é uma das importantes contribuições deste trabalho, bem como, o encontro de pessoas com interesses similares, direcionando o aprendizado deste indivíduo, à medida em que diminui o escopo de busca dentro de um enorme universo de possibilidades e oportunidades de aprendizado, que é a Internet.

Tanto num ambiente presencial quanto virtual, o que importa é a correlação entre possíveis pares com o indivíduo em foco. No meio virtual, contudo, há vantagens devido à possibilidade de automatizar o processo no encontro desses pares, além de considerar um número maior de indivíduos.

Propomos um modelo de combinação social que identifica os pares, de acordo com as teorias de aprendizagem. A aplicação do modelo permite a identificação de pessoas com interesses similares, contribuindo para o aprendizado do indivíduo, a sua transformação e a da rede social de que ele participa. Essa transformação está baseada nos processos cognitivos do indivíduo que se modifica ao interagir com outros, segundo Vygostky [23] em Formação Social da Mente, p. 19.

Na Seção 2 apresentamos o Modelo Oraculous detalhando seu funcionamento. Na Seção 3 são relatados os resultados do estudo de caso. Na Seção 4 apresentamos 
alguns trabalhos relacionados e depois as conclusões desse artigo e a possibilidade de trabalhos futuros.

\section{Modelo Oraculous}

O modelo Oraculous é baseado na premissa de que as pessoas interagem muitas vezes colaborativamente ao usar as redes sociais. Usuários podem aprender com colaboradores que compartilham seus conhecimentos. Uma rede que contém mecanismo de combinação social amplia o seu valor, à medida que organiza as pessoas por seus interesses, formando uma rede de pares. As pessoas podem encontrar outras levando em conta informações explícitas sobre seu domínio de conhecimento e ainda utilizam seus pares como modelo cognitivo para auxiliar o processo de aprendizagem.

A modelagem de redes sociais desloca o foco da informação para o indivíduo e para suas redes de conhecimento, traz o agente da informação para o centro da operação e define o relacionamento social como legítimo e atuante na divulgação do conhecimento. Realizar o intento original da Internet que para Tim Berners-Lee, inventor da Word Wide Web, é um espaço de informação através do que as pessoas possam se comunicar, mas uma comunicação num caminho especial, criando uma rede de conhecimento. Isto implica em modelar o relacionamento social para compreender e aprimorar a forma como o conhecimento se dissemina e como a aquisição do conhecimento se dá na propagação dele, através das redes sociais. O modelo deve representar os grafos pelos quais esta propagação ocorre.

Os padrões ${ }^{1}$ sociais $^{2}$ permitem representar grupos, suas redes de relacionamentos e relações entre grupos. Esses padrões são exemplos de relacionamentos interpessoais a serem seguidos. Tais exemplos criam grupos com interesses em comum. As várias formas de relações desses grupos sociais são mapeadas para formar os modelos informatizados, representações da realidade em ambientes virtuais. Tais representações já existem no mundo presencial há muito tempo. No mundo virtual essas redes conquistam um número cada vez maior de pessoas, criam várias maneiras e motivos para formar relacionamentos, dentre eles a aquisição do conhecimento.

Assim, os Sistemas de Combinação Social (SCS) filtram os subgrupos de indivíduos relacionados por suas semelhanças em interesses, com intuito de aprimorar a colaboração e interação, bem como facilitar a aquisição

\footnotetext{
${ }^{1}$ Padrão é o mesmo que modelo, paradigma. É aquilo que serve de referência, segundo o dicionário Presbiram.. http://www.priberam.pt/dlpo/padr\%C3\%A3o

2 Padrões Sociais vêm da ocorrência de fatos sociais, por exemplo, casamento, formas de agir, sistema financeiro, regras religiosas, jurídicas e outras. No contexto do presente trabalho, tais fatos sociais podem ser exemplificados como formas de organizer o aprendizado..[24]
}

do conhecimento através desses subgrupos. O Oraculous é um SCS que usa anotações que um indivíduo faz sobre páginas da Internet para modelar a combinação entre estes indivíduos. Ele modela uma rede de usuários de serviço de anotação de páginas e estabelece uma rede de relacionamentos entre eles, baseada nestas anotações. A partir destas redes, o Oraculous define subgrupos de indivíduos que apresentam similaridades, segundo um conjunto de critérios de combinação.

O modelo Oraculous constitui-se num serviço que pode ser usado por outros sistemas clientes; por exemplo, as redes sociais. Para melhor entender este modelo ele será apresentado em dois aspectos, a visão geral e a visão detalhada. A visão geral trata do modelo, com seus componentes interagindo com outros sistemas adjacentes. Nesta visão descreve-se . como se dá o fluxo das informações entre o Oraculous e as partes que estão ao seu redor. Cada uma dessas partes fornece e/ou recebe as informações que irão contribuir para o encontro de pessoas com interesses similares e o aprendizado do indivíduo. O Oraculous é agregado a um ambiente já existente, interage com os sistemas clientes recebendo requisições de combinação social, e retorna grupos de indivíduos que combinam segundo os critérios dados.

A visão detalhada é representada pela especificação de um conjunto de heurísticas para encontrar o modelo de processo cognitivo mais adequado aos casos de interesses do indivíduo. Para isso, utilizam-se informações extraídas do ambiente. Mais informações sobre essa visão são mostradas na Seção 2.2.

\subsection{Visão Geral}

Diversos aplicativos na Internet são baseados em redes sociais. Estas redes informatizadas ampliam as possibilidades de relacionamento entre pessoas e aceleram a possibilidade de interação entre elas, explicando o grande sucesso desses aplicativos.

As redes sociais virtuais são modelos informatizados das redes sociais do mundo real que permitem representar claramente quais são os relacionamentos entre pessoas e registrar permanentemente suas ações e interações. $\mathrm{O}$ crescimento e a popularização destas redes mostram que a informatização vem sendo um instrumental importante no relacionamento humano. Esses sistemas informatizados podem ser concebidos para conduzir o comportamento social de modo a obter o melhor do convívio humano.

Nesse contexto, o modelo proposto pode ser dividido em alguns componentes. Sistema Cliente: é a aplicação ou usuário interessado em formar relacionamentos baseados na combinação social. As informações relevantes são explicitadas pelo usuário do sistema cliente. Dessa maneira, um interesse é evidenciado para que o Oraculous indique um conjunto de pares que servirá de modelo 
cognitivo para o usuário. Requisição é a solicitação de combinação social que define um tema e/ou uma teoria de aprendizado. Opcionalmente, a solicitação pode ser realizada através de um indivíduo para criar uma sub-rede de pessoas, que é constituída de acordo com os critérios de combinação estabelecidos pelo ambiente. O modelo Oraculous processa as heurísticas a partir da requisição combinante; em seguida, retorna um grupo pareado, de acordo com o modelo de processo cognitivo, discutido na Seção 2.2. Grupo Pareado é a lista de indivíduos pareados segundo a requisição. O componente Grupo Pareado apresenta o resultado da heurística executada; assim, a investigação desses resultados por parte do usuário favorece a ampliação do conhecimento sobre o interesse pesquisado, a partir da utilização da observação do processo de aquisição cognitiva de seus pares.

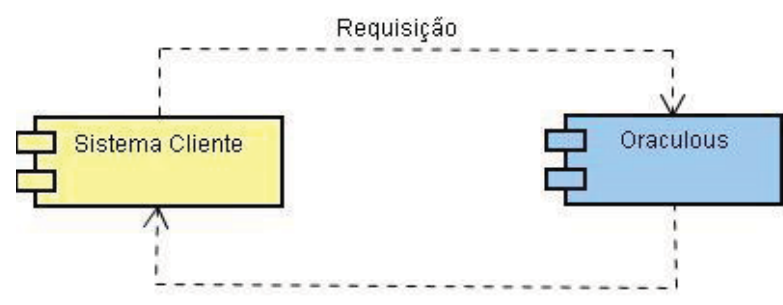

Grupo Pareado

Figura 2.1 Visão Geral - Modelo de Processo Cognitivo - Oraculous

\subsection{Visão Detalhada}

Um modelo de combinação social é uma forma de recomendação que sugere como pessoas compartilham certas características. Deve definir os indivíduos e relacionamentos, assim como registrar suas ações para determinar afinidades. Baseado nisso, no modelo Oraculous, os indivíduos representam anotadores de páginas, e seus relacionamentos são as páginas e anotações que eles têm em comum. A filtragem se dá através de restrições que são realizadas ao se contabilizar quais características comuns importam para a formação de grupos pareados. $\mathrm{O}$ comportamento que se quer estudar é como as teorias de aprendizagem podem afetar os grupos que serão formados pela filtragem. As teorias de aprendizagem fundamentam como se dá a aquisição do conhecimento, e esta aquisição pode ser modelada - usada como referência através da filtragem dos relacionamentos entre indivíduos. A visão pormenorizada deste modelo é o detalhamento do mecanismo de combinação social, denominado de modelo de processo cognitivo, de acordo com as teorias de aprendizagem existentes. $\mathrm{O}$ modelo proposto utiliza a correlação de Pearson ${ }^{1}$ para mensurar o grau de semelhança entre o indivíduo que realiza a pesquisa e as pessoas interessadas em um mesmo assunto nas sete das oito abordagens. Essa avaliação vai ao encontro da teoria de Kelly [4]Psicologia dos Construtos Pessoais que explica em termos de aprendizagem o porquê de encontrar pessoas com interesses similares e de mensurar o grau de semelhança entre o indivíduo e seus pares.

A teoria de Kelly justifica não só o cálculo de grau de semelhança, mas também a similaridade apenas no interesse em questão. Este modelo pode ajudar no sistema de construção que é o meio pelo qual o indivíduo representa seus construtos pessoais. O indivíduo, através da observação de seus construtos pessoais. $\mathrm{O}$ indivíduo, através da observação de seus pares [1], modifica o seu sistema de construção à medida que ele constrói interpretações em relação ao interesse em questão, ou a outros interesses similares ao seu - corolário da construção ou interpretação. Isso se dá ao identificar o que é comum e contrastante em seu aprendizado em relação ao de outra pessoa corolário da comunalidade. Para mensurar o grau de semelhança entre o indivíduo e pessoas com interesses similares é utilizada a Equação (1) - Correlação de Pearson - demonstrada a seguir:

$$
r=\frac{\sum_{i=1}^{n}\left(x_{i}-\bar{x}\right)\left(y_{i}-\bar{y}\right)}{\sqrt{\sum_{i=1}^{n}\left(x_{i}-\bar{x}\right)^{2}} \cdot \sqrt{\sum_{i=1}^{n}\left(y_{i}-\bar{y}\right)^{2}}}
$$

Onde: $\mathrm{r}=$ Coeficiente de Pearson; $\mathrm{x}=$ USUARIO_ALVO; $y=O U T R O \_U S U A R I O$.

O conjunto USUARIO_ALVO contém o usuário que será avaliado e o conjunto de seus interesses. Ele pode ser construído de acordo com o escopo desejado, considerando o interesse em questão, os recentes ou todos os interesses do usuário. O conjunto OUTRO_USUARIO contém os usuários a serem comparados com o usuário avaliado. Quanto aos interesses considerados podem ser o em questão ou recentes ou todos [7].

Além da teoria de Kelly, as abordagens que compõem o modelo são baseadas também na aprendizagem vicariante [1] - em que a observação do comportamento do

\footnotetext{
1 Correlação de Pearson mede a correlação entre duas variáveis aleatórias, através da divisão da covariância dessas duas variáveis, pelo produto de seus desvios padrão. O coeficiente da relação é o resultado deste cálculo. Este valor varia entre 1 e -1 . O valor 0 (zero) significa dizer que não existe relação linear; o 1(um) indica que existe uma forte correlação linear; e o -1 (menos um) indica uma relação linear inversa. Assim, quanto mais próximo de 1 e -1 , mais forte é a associação linear entre as duas variáveis. [7]
} 
outro viabiliza a aquisição do conhecimento - e no conceito de Zona de Desenvolvimento Proximal (ZDP), elaborado por Vygotsky [9]. A ZDP é a distância entre o nível de desenvolvimento real, determinado pela capacidade de resolver problemas independentemente, e o nível de desenvolvimento potencial, determinado pela resolução de um problema com ajuda de alguém, ou através da colaboração de outras pessoas. $\mathrm{O}$ aprendizado ideal ocorre quando a pessoa recebe input lingüístico de nível imediatamente superior ao seu. Assim, o desenvolvimento potencial deste indivíduo, ainda não completou o processo, pois são conhecimentos fora de seu alcance atual, embora potencialmente atingíveis. Esses conhecimentos podem ser construídos com a ajuda de seus pares, através da combinação social. O modelo, portanto, contempla várias formas de encontrar pessoas, ampliando a oportunidade de aprendizado. A Equação 2 - Conjunto de Pares - representa a abstração do modelo.

$$
\mathrm{P}=\left\{\mathrm{x}_{\mathrm{i}} \in \mathrm{A} \text { e } \mathrm{x}_{\mathrm{i}} \in \mathrm{B} \mid \mathrm{x}_{\mathrm{i}} \in(\mathrm{A} \cap \mathrm{B}) \forall \mathrm{i} \in \mathrm{N}\right\}
$$

Onde: $\mathrm{P}=$ conjunto de pares; $\mathrm{xi}=$ é a pessoa $\mathrm{i}$ avaliada para entrar no conjunto $\mathrm{P} ; \mathrm{A}=$ Pessoas que referenciam o artefato utilizado para busca dos pares; $\mathrm{B}=$ Pessoas que referenciam os artefatos mais populares, vinculados ao artefato utilizado para busca dos pares.
Suponha que o usuário pesquise pelo termo: "música" e seus pares são: $\mathrm{P}=\{$ Marco, Julio, Amanda, Juliana\}. Resultado obtido a partir dos conjuntos A e B a seguir:

Seja $\mathrm{A}=\{$ Elias, Jose, Marco, Julio, Amanda, Juliana\} são pessoas que fazem referência ao termo "música" e $\mathrm{B}=\{$ Isis, Tais, Jose, Marco, Julio, Amanda, Juliana $\}$ são as pessoas que fazem referências aos termos mais populares relacionados ao termo "música". Fazendo a interseção entre os dois conjuntos obtém-se o conjunto de pares $\mathrm{P}$ descrito anteriormente.

Construiu-se, portanto, o conjunto de pessoas que tem interesse no mesmo assunto que pode fazer parte do seu grupo de interesse. A partir, da formação do conjunto P é aplicada a Equação 2, caso se deseje avaliar o grau de semelhança entre o USUARIO_ALVO, o usuário do ambiente, e os indivíduos deste conjunto, que é realizada a partir da avaliação do que foi postado em comum com os pares. Para cada artefato postado é atribuído o peso 1. Para atribuir pesos diferentes observe o Modelo de Referência, descrito na seção 4 sobre trabalhos relacionados.

A seguir são apresentadas todas as abordagens do Modelo Oraculous, em que apenas as descritas nas Seções 2.2.1, 2.2.2 e 2.2 .3 são consideradas nos resultados deste artigo.

\section{Veja o exemplo:}


Promovendo a aprendizagem através das redes sociais

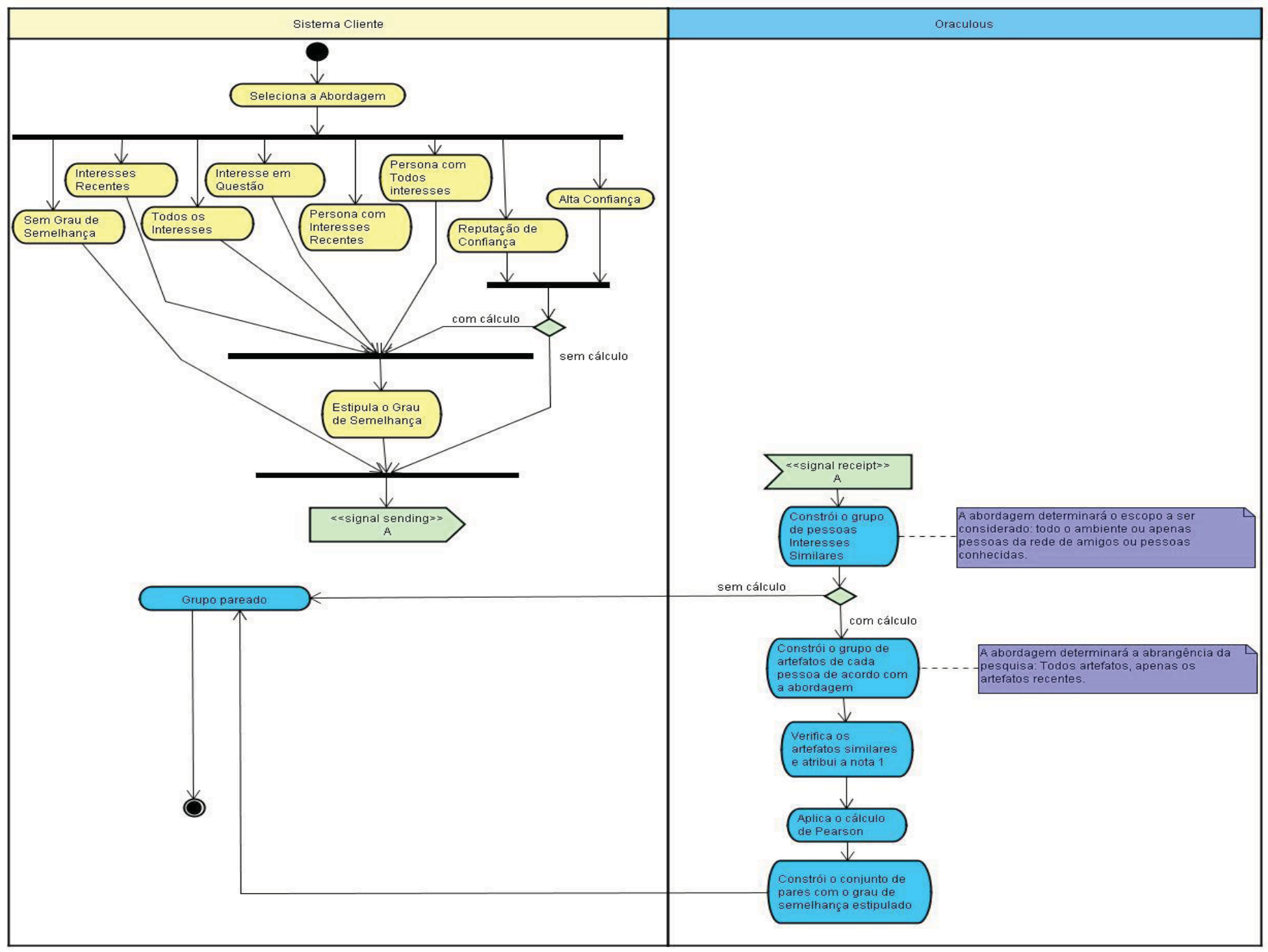

Figura 2.2 : Visão Detalhada do Modelo de Processo Cognitivo - Oraculou 


\subsubsection{Similaridade sem grau de semelhança}

Essa abordagem está relacionada ao corolário sociabilidade, descrito por Kelly [5]. Tal corolário afirma que a pessoa pode ter um papel em um processo social envolvendo a outra. Este papel é o entendimento de uma pessoa sobre o que pensam os outros associados a uma tarefa.

Todas as pessoas encontradas, como resultado dessa abordagem, possuem artefatos vinculados ao mesmo interesse que contribuirá com o processo de aprendizagem do indivíduo. Na prática, não utiliza nenhum cálculo de similaridade, pois faz parte do caso de interesse em que o indivíduo quer investigar todas as pessoas com os mesmos interesses, sem mensurar o grau de semelhança com outros indivíduos em um conjunto de interesses. Portanto, o conjunto de pares retornado são todas as pessoas contidas no conjunto $\mathrm{P}$, Equação 2, mostrado no item anterior. Nem sempre o assunto de interesse é compartilhado pelos pares semelhantes; sendo assim fazer o cálculo de similaridade poderá retornar um conjunto vazio de pares. Além disso, o indivíduo pode estar interessado em explorar um conjunto mais abrangente de pares, sem restringir o resultado, através do cálculo de similaridade.

\subsubsection{Similaridade com grau de semelhança, considerando interesses recentes}

Esta abordagem está vinculada ao conceito de ZDP de Vygotsky [9], pois ao encontrar pessoas semelhantes, o indivíduo pode identificar interesses relacionados ao interesse inicial que ainda não amadureceram, mas que estão no processo de maturação. Além disso, os corolários de Kelly [5] justificam a existência da similaridade não só nesta abordagem, mas também nas outras que realizam este cálculo.

Ela está ligada ao caso de interesse em que o indivíduo quer observar outros assuntos que também lhe interessam, através dos pares semelhantes. Inicialmente, constrói o conjunto de pares com o mesmo interesse do indivíduo em questão; em seguida, avalia cada um dos pares e mensura o grau de semelhança com este indivíduo, como mostra o conjunto solução $\mathrm{S}$ da Equação 3 Conjunto Solução.

$$
s=\left\{x_{i} \in P \leftrightarrow r_{x i} \geq \alpha\right\}
$$

Onde: $\mathrm{x}_{\mathrm{i}}=$ é a pessoa $\mathrm{i}$ avaliada para entrar no conjunto $\mathrm{P} ; \mathrm{P}=$ conjunto de pares, mostrado na Equação $2 ; \mathrm{r}_{\mathrm{xi}}=$ coeficiente de Pearson calculado para a pessoa $\mathrm{x}_{\mathrm{i}} ; \alpha=$ coeficiente estabelecido.

O conjunto de pares retornado pode ser vazio, pois ao avaliar apenas os interesses recentes desses pares para mensurar a similaridade, pode ocorrer que dentro deste grupo avaliado, não seja encontrado ninguém semelhante com grau de similaridade estabelecido.

Avaliar interesses recentes é a grande diferença desta seção para a próxima. Na prática, a mudança está embutida no cálculo do coeficiente de Pearson; de modo que os conjuntos $\mathrm{X}$ e $\mathrm{Y}$ da Equação 1 são construídos considerando os interesses recentes do indivíduo.

A vantagem desta abordagem é a rapidez no cálculo de similaridade, já que o conjunto de interesses avaliado para cada um dos pares é menor em relação à abordagem seguinte, que avalia todos os interesses do indivíduo. Embora avaliar todos os interesses seja mais completo, por trazer um resultado maior de pares semelhantes, mas pode se tornar inviável, dependendo da quantidade de interesse de cada par.

\subsubsection{Similaridade com grau de semelhança, considerando todos os interesses}

Esta abordagem também está relacionada ao conceito de ZDP de Vygotsky [9] e aos corolários de Kelly [5], a vantagem é a abrangência ao mensurar a semelhança. Por ser maior, isto significa um resultado mais completo, pois não necessariamente os pares vinculados a um interesse estão estudando recentemente os mesmos assuntos que o indivíduo em questão.

Diferente da abordagem anterior inclui todos os interesses das pessoas a serem comparadas, considerando até as que não estão estudando recentemente o assunto em questão. $\mathrm{O}$ conjunto solução $\mathrm{S}$, Equação 3, é o mesmo do item anterior, a diferença está na construção dos conjuntos X e Y, mostrados na Equação 1. Neste caso, são considerados todos os interesses do indivíduo.

\subsubsection{Persona com interesses recentes}

O conceito de persona é embasado na ideia de Cooper [14] que afirma que o indivíduo possui várias visões de si mesmo. Os interesses do indivíduo são separados por setores de sua vida; interesses relacionados ao seu trabalho, são diferentes dos interesses relacionados na sua vida pessoal. A ideia é separar o indivíduo em personas, através dos seus interesses explícitos no ambiente, encontrar e avaliar a similaridade delas com a do outro. Esta é a grande diferença do conjunto P, mostrado na Seção 2.2, Equação 2. Sendo assim, os conjuntos A e B são formados por personas, e não mais por pessoas, o coeficiente de Pearson calculado será da persona e o conjunto solução $\mathrm{S}$ é o mesmo da Seção 2.2.2, Equação 3, em que serão avaliados apenas os interesses recentes das pessoas para efeito de cálculo do coeficiente. 


\subsubsection{Persona com todos os interesses}

Da mesma maneira que a abordagem anterior utiliza o conceito de persona, cuja única diferença é o conjunto de interesses avaliados. Neste caso, todos os interesses são considerados.

O conjunto solução S, Equação 3, é o mesmo da seção anterior, a grande diferença está no cálculo do coeficiente de Pearson para cada persona, assim os conjuntos X e Y da Equação 1 considera todos os interesses da persona.

\subsubsection{Alta confiança}

Este conceito é retirado da teoria de confiança interpessoal de Julian Rotter [16] que explica a construção da confiança explícita nas pessoas, estabelecida, neste contexto, quando o indivíduo inclui um par na rede de amigos. Supomos, assim, que dentro da rede de amigos existem pessoas confiáveis que podem ajudá-lo a adquirir o aprendizado em um determinado assunto. Nessa abordagem, o universo pesquisado é a rede de amigos. O grau de similaridade poderá, contudo, restringir ainda mais o resultado, por isso, ficará sob responsabilidade do indivíduo estabelecer o fator de semelhança desejado.

Esta abordagem também vai ao encontro com algumas das atitudes que no entender de Rogers [5] caracterizam o facilitador da aprendizagem, em nosso caso, esse facilitador são os pares, são elas: prezar, aceitar, confiar a aceitação do outro indivíduo como uma pessoa separada, tendo seu próprio valor; é uma confiança básica, é acreditar que de alguma maneira essa outra pessoa é merecedora de confiança.

$\mathrm{O}$ conjunto solução $\mathrm{S}$ é o mesmo da Seção 2.2.2, Equação 3, a diferença está na construção dos conjuntos $\mathrm{A}$ e B, importantes para a formação do conjunto $\mathrm{P}$, mostrado na Equação 2. Para construir A e B são considerados, ao invés do universo "todo o ambiente" apenas as pessoas contidas na "rede de amigos".

\subsubsection{Reputação de confiança}

Esta abordagem está de acordo com a ideia de Fürst [15] sobre salto cognitivo. Para avaliar este salto, alcançado pelo indivíduo antes da combinação social comparamos o que uma pessoa indicou como interessante para ele, com o que ele aceitou desta indicação. Em um segundo momento, faz-se esta mesma avaliação após a combinação social. A ideia é constatar que com a combinação social o indivíduo multiplica a possibilidade de aprender, pois o indivíduo aceitará artefatos de modo mais direcionado ao seu interesse. Nessa abordagem, é realizado o cálculo de similaridade, em que o fator de semelhança será o estabelecido pelo indivíduo.
Ao indicar um artefato, a pessoa está reputando aquele artefato como confiável. A partir do universo de pessoas que reputam artefatos a outras, será realizado a busca por pares em determinado interesse. Normalmente esse grupo é constituído por pessoas conhecidas ou próximas, mas que não necessariamente fazem parte da rede de amigos que por reputarem artefatos confiáveis tornamse confiáveis. Esta é a diferença desta abordagem, em relação à anterior - na construção do conjunto solução $\mathrm{S}$, Equação 3, mais precisamente, na formação dos conjuntos A e B, importantes para o conjunto P, Equação 2, usados em $\mathrm{S}$, são considerados as pessoas que reputam artefatos a outras, ao invés do universo "todo o ambiente" ou "rede de amigos".

\subsubsection{Similaridade com grau de semelhança, considerando o interesse em questão}

Esta abordagem está embasada no conceito de ZDP de Vygotsky em que o indivíduo quer avaliar a semelhança com seus pares considerando apenas o interesse em questão, mas não em relação a um conjunto de interesses como proposto nas abordagens anteriores. Os corolários de Kelly propõem a similaridade considerando esta abrangência, mas em se tratando de uma tarefa o corolário da sociabilidade é mais adequado para justificar esta abordagem, pois se refere à troca de experiências com outras pessoas similares em relação a uma tarefa, em que, no contexto deste trabalho, esta troca é realizada através da observação.

Esses conceitos tornam-se concretos quando se calcula o grau de semelhança com outras pessoas apenas em relação ao interesse explicitado pelo indivíduo Para efetuar este cálculo é utilizado a equação de Pearson, apresentado na Equação 1. O conjunto solução $\mathrm{S}$ é o mesmo da Seção 2.2.2, Equação 3. A diferença está na construção dos conjuntos X e Y, importantes para o cálculo do coeficiente de Pearson, Equação 1. Neste caso, tais conjuntos são construídos considerando apenas o interesse em questão. 


\section{Metodologia}

As hipóteses que orientam este trabalho são o fio condutor para a avaliação do modelo de combinação social, descrito na Seção 2: Hipótese 1 - H1: a combinação social proporciona a formação de uma rede de pares por interesse e Hipótese 2 - H2: a combinação social aprimora a aquisição do conhecimento, através da observação de como seus pares aprenderam.

Para avaliarmos as hipóteses utilizamos as seguintes métricas: para a H1 contabilizamos o número de amigos armazenados nos sites Oraculous, solução implementada, e Delicious. Essas informações foram coletadas após a execução da investigação sobre assunto "microblogging", proposto aos participantes e para a $\mathrm{H} 2$ aplicamos um teste inicial e outro após a execução da tarefa, sobre o assunto proposto.

A Figura 3.1 mostra a interface do mecanismo de combinação social - Oraculous -, que evidencia a formação da rede de pares, como uma das opções do menu. $\mathrm{O}$ resultado dessa evidência pode ser consultado na Seção 4, no experimento realizado.

A amostra dessa pesquisa foi representada por um conjunto de pessoas convidadas, das que concordaram em participar, tivemos o cuidado em organizá-las em dois grupos (experimental e controle) de maneira a respeitar algumas variáveis relevantes à pesquisa: pessoas que conhecem o autor deste trabalho; pessoas que possuem familiaridade com o site Delicious e; pessoas que conhecem o presente trabalho. Das 160 (cento e sessenta) pessoas convidadas, apenas 27 (vinte e sete) aceitaram colaborar com a realização da pesquisa. Tal número foi pouco representativo para que os resultados sejam generalizados no presente trabalho. Essa quantidade de pessoas para as hipóteses $\mathrm{H} 1$ e H2, contudo, foi suficiente para verificarmos sua validade.
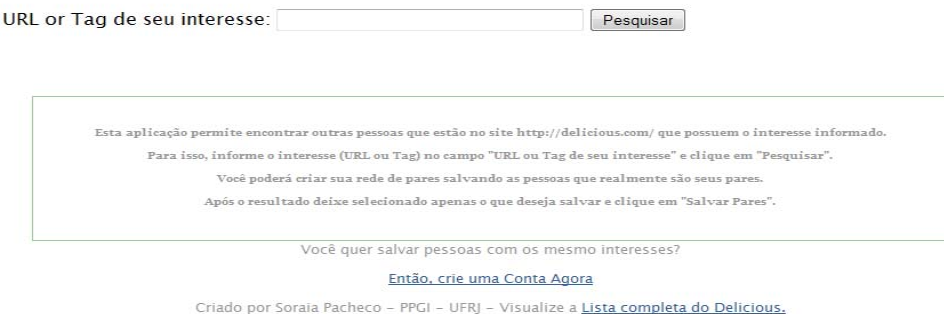

Figura 3.1: Interface do mecanismo de combinação social - Oraculous

O delineamento utilizado foi um quasi-experimento , comparando o grupo experimental com o grupo controle. Segundo a notação descrita [2], significa que a amostra considerada foi dividida em grupos: experimental e controle. Tanto o grupo experimental quanto o grupo controle realizaram um pré-teste sobre o assunto sugerido (microblogging), em seguida, informamos a descrição da tarefa aos participantes. De forma que foi dado um tratamento diferenciado aos participantes, representados por $\mathrm{X} 1$ e X2, em que o grupo controle utilizou apenas o site Delicious e, o grupo experimental utilizou o Delicious e
Oraculous para investigar sobre o tema proposto. Ao final do processo, os dois grupos realizaram um pós-teste, com as mesmas questões do pré-teste, como mostra a Tabela 3.1 . 


\begin{tabular}{|c|c|c|c|c|}
\hline & Questões & Dimensão & $\begin{array}{l}\text { Polaridade } \\
\text { Textual }\end{array}$ & $\begin{array}{l}\text { Qual questão é } \\
\text { validada?1 }\end{array}$ \\
\hline 1 & Sei o que é microblogging. & Geral & POSITIVA & \\
\hline 2 & Conheço pelo menos um site de microblogging. & Geral & POSITIVA & \\
\hline 3 & Conheço vários sites de microblogging. & Geral & POSITIVA & 2 \\
\hline 4 & Sei como um aplicativo poderia se beneficiar com microblogging. & Geral & POSITIVA & \\
\hline 5 & $\begin{array}{l}\text { Sei como responder as pessoas e colocar tags em um microblog- } \\
\text { ging. }\end{array}$ & Geral & POSITIVA & \\
\hline 6 & Já li resenhas sobre microblogging em sites de discussão técnica. & Técnico & POSITIVA & \\
\hline 7 & Já li sobre vários aplicativos que são usados em microblogging. & Técnico & POSITIVA & \\
\hline 8 & $\begin{array}{l}\text { Conheço vários clientes de desktop e baseados na web para micro- } \\
\text { blogging. }\end{array}$ & Técnico & POSITIVA & \\
\hline 9 & Conheço uma iniciativa para a interoperabilidade entre microblogs. & Técnico & POSITIVA & \\
\hline 10 & Conheço aplicativos de microblogging que já interoperam entre si. & Técnico & POSITIVA & 9 \\
\hline 11 & $\begin{array}{l}\text { Conheço um formato XML que é usado para exportar a rede social } \\
\text { de um microblog. }\end{array}$ & Técnico & POSITIVA & \\
\hline 12 & Conheço um ou mais microblogs que exportam com esse formato. & Técnico & POSITIVA & \\
\hline 13 & $\begin{array}{l}\text { Conheço sites de microblogging que estão se expandindo e com- } \\
\text { prando seus concorrentes. }\end{array}$ & Geral & POSITIVA & 20 \\
\hline 14 & $\begin{array}{l}\text { Sei nomear um ou mais sites de redes sociais que incorporaram } \\
\text { microblogging. }\end{array}$ & Geral & POSITIVA & \\
\hline 15 & Este assunto de microblogging permanece um mistério para mim. & Geral & POSITIVA & 1 \\
\hline 16 & Este modelo de comunicação é referenciado pelos sites da Web 2.0 & Geral & POSITIVA & \\
\hline 17 & Participo de pelo menos um microblogging. & Geral & POSITIVA & \\
\hline 18 & Conheço pelo menos um gerenciador de microblogging. & Técnico & POSITIVA & \\
\hline 19 & $\begin{array}{l}\text { É difícil encontar resenhas sobre microblogging em sites de análise } \\
\text { técnica. }\end{array}$ & Geral & POSITIVA & 6 \\
\hline 20 & $\begin{array}{l}\text { Conheço sites que já estão oferecendo maneiras de se ganhar di- } \\
\text { nheiro com microblogging. }\end{array}$ & Geral & POSITIVA & \\
\hline 21 & $\begin{array}{l}\text { Não enviei mensagem, nem respondi a ninguém em serviço de } \\
\text { microblogging. }\end{array}$ & Geral & NEGATIVA & 5 \\
\hline 22 & $\begin{array}{l}\text { Conheço mais de um serviço capaz de avaliar a influência de uma } \\
\text { pessoa em uma rede de microblogging. }\end{array}$ & Técnico & POSITIVA & \\
\hline 23 & $\begin{array}{l}\text { Microblogging é um assunto que faz parte do cotidiano das pessoas } \\
\text { há muito tempo. }\end{array}$ & Geral & POSITIVA & 1 \\
\hline 24 & $\begin{array}{l}\text { O modelo de comunicação promovido pelo microblogging é ideal } \\
\text { para uso corporativo. }\end{array}$ & Geral & POSITIVA & \\
\hline 25 & Microblogging é uma tecnologia que não se adequa a educação. & Geral & NEGATIVA & 26 \\
\hline 26 & $\begin{array}{l}\text { Conheço microbloggings que se destinam à comunicação entre } \\
\text { alunos e professores. }\end{array}$ & Geral & POSITIVA & \\
\hline 27 & $\begin{array}{l}\text { Este modelo de comunicação não é referenciado pelos sites da Web } \\
2.0\end{array}$ & Geral & NEGATIVA & 16 \\
\hline 28 & Não acompanho nenhum site de microblogging. & Geral & NEGATIVA & 17 \\
\hline 29 & Microblogging é uma tecnologia que não se adequa para educação. & Geral & NEGATIVA & 25 e 26 \\
\hline 30 & $\begin{array}{l}\text { Não é possível organizar conversações em um site de microblog- } \\
\text { ging. }\end{array}$ & Geral & NEGATIVA & 5 \\
\hline
\end{tabular}

Tabela 3.1 Matriz de Referência do Pré-teste e Pós-teste

\footnotetext{
${ }^{11}$ Qual questão é validada? => Esta coluna mostra as questões que foram criadas para verificar a coerência das respostas de cada participante.
} 


\section{Análise dos Dados}

A Tabela 4.1 mostra a identificação adotada para o grupo controle e experimental nas análises apresentadas nos próximos itens.

\begin{tabular}{|l|c|c|}
\hline \multicolumn{1}{|c|}{ Grupo } & Id. & Sites usados durante a tarefa \\
\hline Controle & 1 & Delicious \\
\hline Experimental & 2 & Delicious e Oraculous \\
\hline
\end{tabular}

Tabela 4.1 Identificação nas análises do grupo controle e expermental

Vale ressaltar que não haviam diferenças relacionadas às tarefas enviadas aos respondentes até a realização do pré-teste, os dois grupos receberam as mesmas instruções. Após a realização do pré-teste, os participantes receberam informações diferentes para execução da tarefa, em que o assunto proposto era o mesmo (microblogging), diferenciando apenas na sugestão dos sites que seriam usados para investigar o assunto proposto. Dessa maneira, o grupo controle investigou o tema usando o Delicious e o grupo experimental investigou o mesmo tema usando o Oraculous e Delicious. Em nossa amostra, as pessoas que não participaram de algumas das etapas foram retiradas da análise, assim não atribuímos valores para casos perdidos.

\subsection{Hipótese - H1}

$\mathrm{Na}$ hipótese $\mathrm{H} 1$, é possível afirmar pelos resultados apresentados no Gráfico 4.1 que uma ferramenta de combinação social pode aumentar a rede de social do indivíduo na Internet, como pode ser observado pela quantidade de pares armazenados com o uso do Oraculous, em relação ao Delicious. Tal constatação aponta para a viabilidade dessa hipótese - H1 - "aumento da rede de amigos potencializada com a combinação social".

Analisamos os links (Qtd_Urls) e pessoas(Qtd_Pares) adicionadas no Delicious quanto no Oraculous. Observamos um índice expressivo de pessoas que não adicionaram links no grupo 2(experimental), em contrapartida, o grupo 1(controle) não adicionou pares ou pessoas, embora esta prática tenha sido incentivada para os dois grupos.

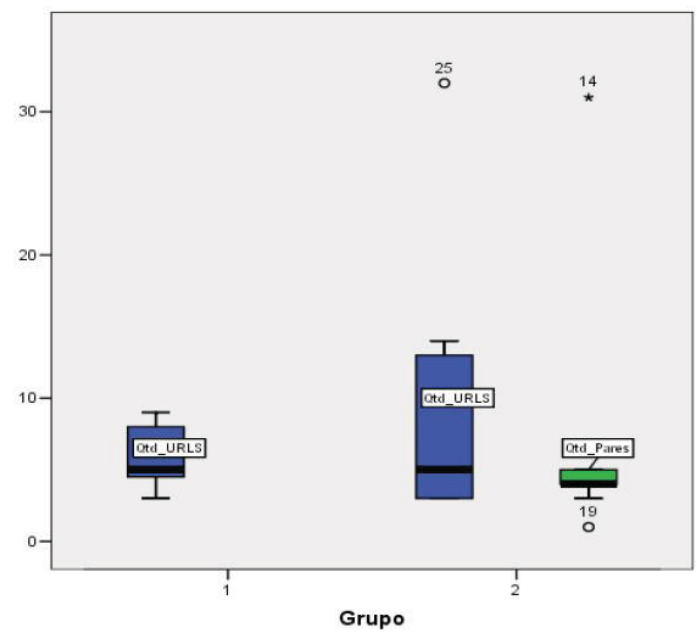

Gráfico 4.1 box plot para análise da tarefa

Notamos que apenas o grupo experimental armazenou pares. Essa constatação nos dá indícios que a solução implementada deixa mais evidente esta prática. Esta atitude mostra a viabilidade da hipótese $\mathrm{H} 1$, sem a necessidade da análise confirmatória, já que o fato de apenas um grupo adicionar pares torna-se inviável a comparação entre os grupos.

Verificamos o $p$-value do Teste $T$, constatamos que o $\mathrm{p}$-value $=0,334>\alpha=0,05$, demonstrando que a diferença entre as médias não é significativa. Tal fato indica que a hipótese nula não deve ser rejeitada, assim tanto o grupo experimental quanto o controle obtiveram um bom desempenho ao armazenar links sobre o tema proposto.

A comparação das médias entre o grupo experimental e controle através do Teste $T$ não foi possível fazer, pois o grupo controle não adicionou nenhuma pessoa à rede social do Delicious.

\subsection{Hipótese - $\mathrm{H} 2$}

Percebemos que no pré-teste houve um índice expressivo nos dois grupos que não se posicionaram nas questões: "16", "19"1, "24", "27N" e"30N"3. Destacamos a questão "19" com $66 \%$ de respondente no grupo 1 (controle) e $80 \%$ no 2 (experimental), que registraram não ter opinião sobre esta questão, como mostra Gráfico 4.2.

\footnotetext{
${ }^{1}$ QPre 19 => É difícil encontar resenhas sobre microblogging em sites de análise técnica.

${ }^{2}$ QPre 24 => O modelo de comunicação promovido pelo microblogging é ideal para uso corporativo.

${ }^{3}$ QPre_30 Negativo => Não é possível organizar conversações em um site de microblogging.
} 


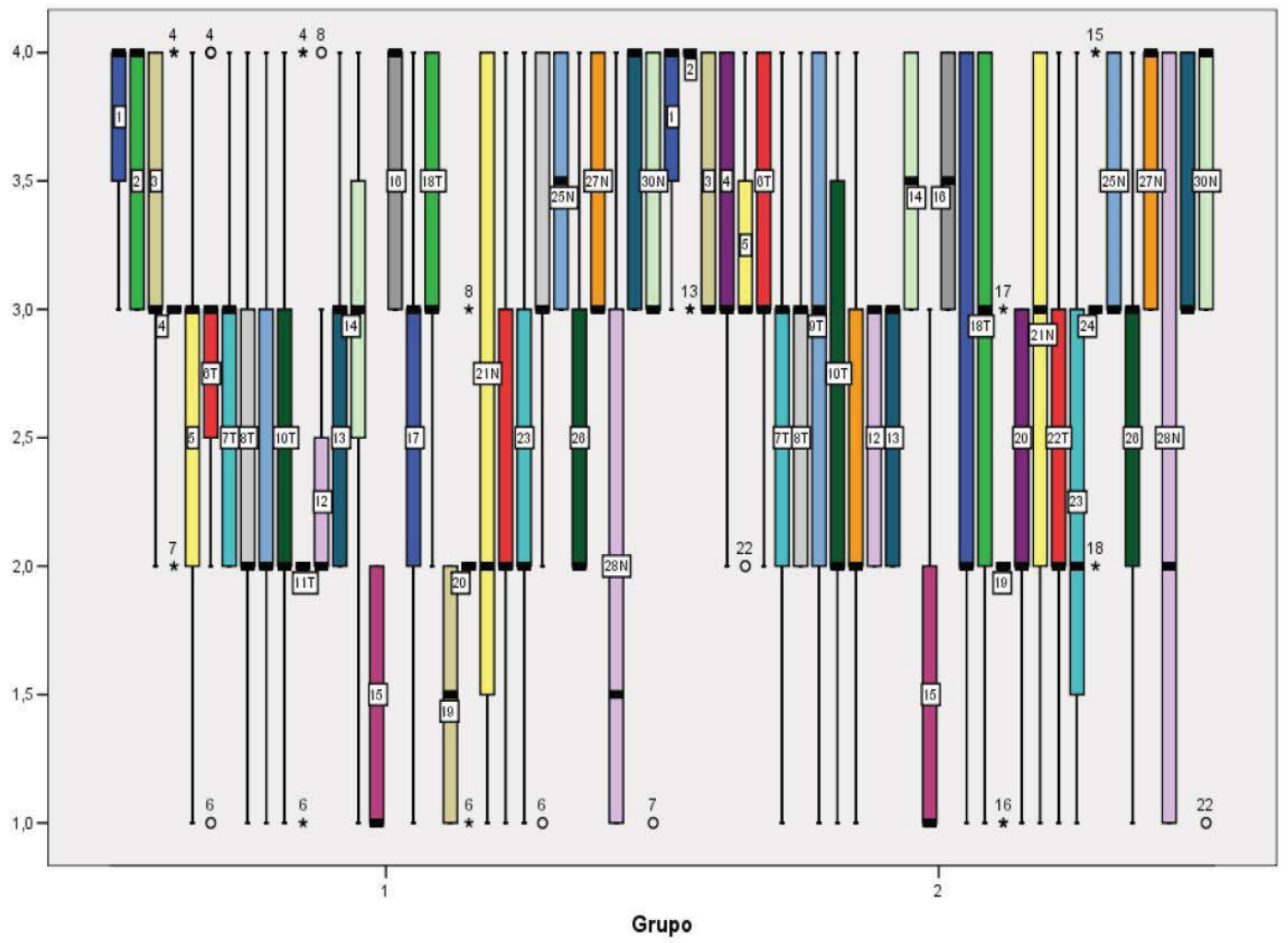

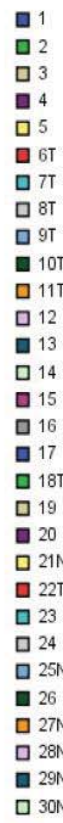

Gráfico 4.2 box plot para análise do pré-teste

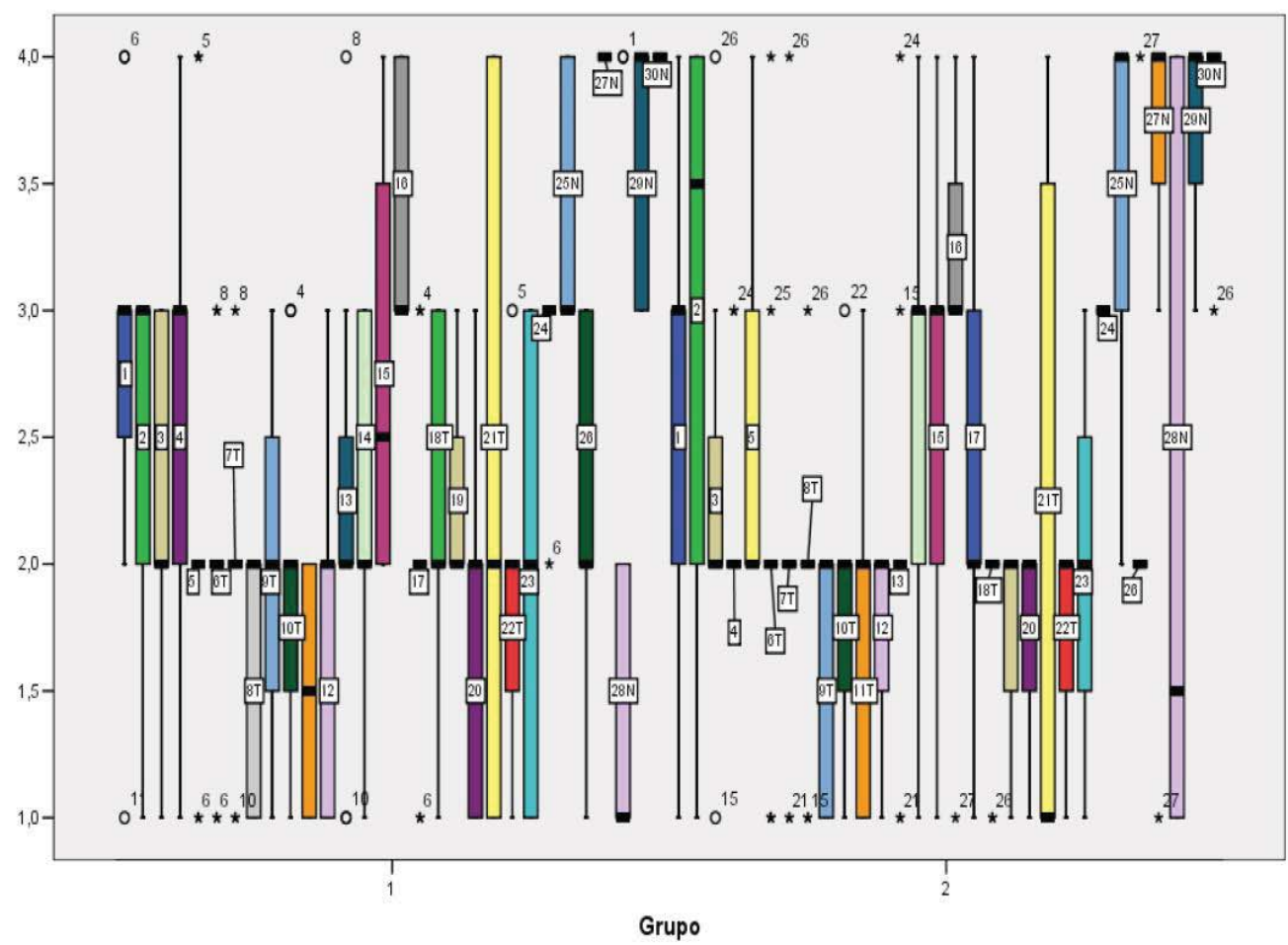

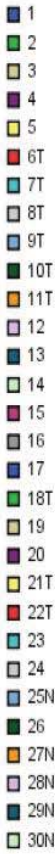

Gráfico 4.3 box plot para análise do pós-teste 
Observamos a existência de dispersão nas respostas, mas, no geral, notamos, pela mediana, que os dois grupos são homogêneos. Essa constatação nos mostra que o objetivo desejado ao construir esses grupos foi alcançado. Tal fato será confirmado com a análise confirmatória, através do Teste $T$.

Em termos proporcionais: $58,3 \%$ do grupo controle responderam pelo menos uma questão discordando da maioria, enquanto, no grupo experimental foram $40,0 \%$. O que nos leva a crer em uma variabilidade alta dos elementos da população, que pode ser encontrada mais no grupo controle do que no experimental.

Constatamos no pós-teste, Gráfico 4.3, uma queda na dispersão das respostas para os dois grupos. No grupo controle alguns dos participantes que registraram respostas diferentes da média, continuam apresentando o mesmo problema, verificado no pré-teste, respostas que discordam da maioria dos respondentes, são eles: os participantes 4(quatro), 6(seis) e 8(oito). Já o 7(sete) não apresentou outliers no pré-teste, mas nesta etapa, mostrou incoerência na questão " 30 ”, em comparação com a questão de validação "5", o que ocasionou o destaque dele com valor extremo, porém nas demais proposições se mostrou coerente. Além disso, observamos que o grupo experimental continua com a mesma quantidade de outliers comparado com o pré-teste.

Notamos que ao comparar a mediana do grupo 1 (controle) com a do grupo 2 (experimental) uma quantidade maior de respondentes no grupo 2 (experimental) que aprenderam sobre o assunto proposto. Além disso, algumas pessoas passaram a ter mais convicção em suas respostas, como pode ser visto com aumento da mediana de algumas questões para a opção 4 (Concordo Fortemente). Tal fato não ocorreu no pré-teste.

Nesta análise, utilizamos dois tipos de métodos: amostras dependentes e independentes. As amostras são dependentes, se considerarmos uma única amostra, assim comparam-se as médias do grupo controle ou experimental no pré e pós testes; são independentes, se considerarmos dois grupos diferentes. Neste caso, comparam-se as médias do controle com as do experimental no pré-teste, em seguida no pós-teste.

Da mesma maneira que as outras análises, usamos o software SPSS. Fizemos a análise da amostra independente através da opção "Independent-Samples T-Test" e a análise da amostra dependente através da opção "PairedSamples T-Test". Conforme orientações do manual encontrado na URL: http://academic.reed.edu/psychology/RDDAwebsite/spss guide/ttests.html e do próprio manual do SPSS.

$\mathrm{Na}$ análise com amostras dependentes, constatamos que o grupo 2(experimental) apresentou um ganho de conhecimento em um número maior de questões do que o grupo controle. O grupo 1 (controle) apresentou diferenças significativas na média em 6 (seis) questões, que representam $20 \%$ do teste. Já o grupo 2 (experimental) teve um ganho em 13 questões, que representam $43 \%$ do teste. Sendo assim, observamos que essa hipótese - H2 mostra-se viável. Se considerarmos apenas essa análise podemos afirmar que a combinação social facilita o ganho no aprendizado, como mostram Gráfico 4.4 e Gráfico 4.5. 


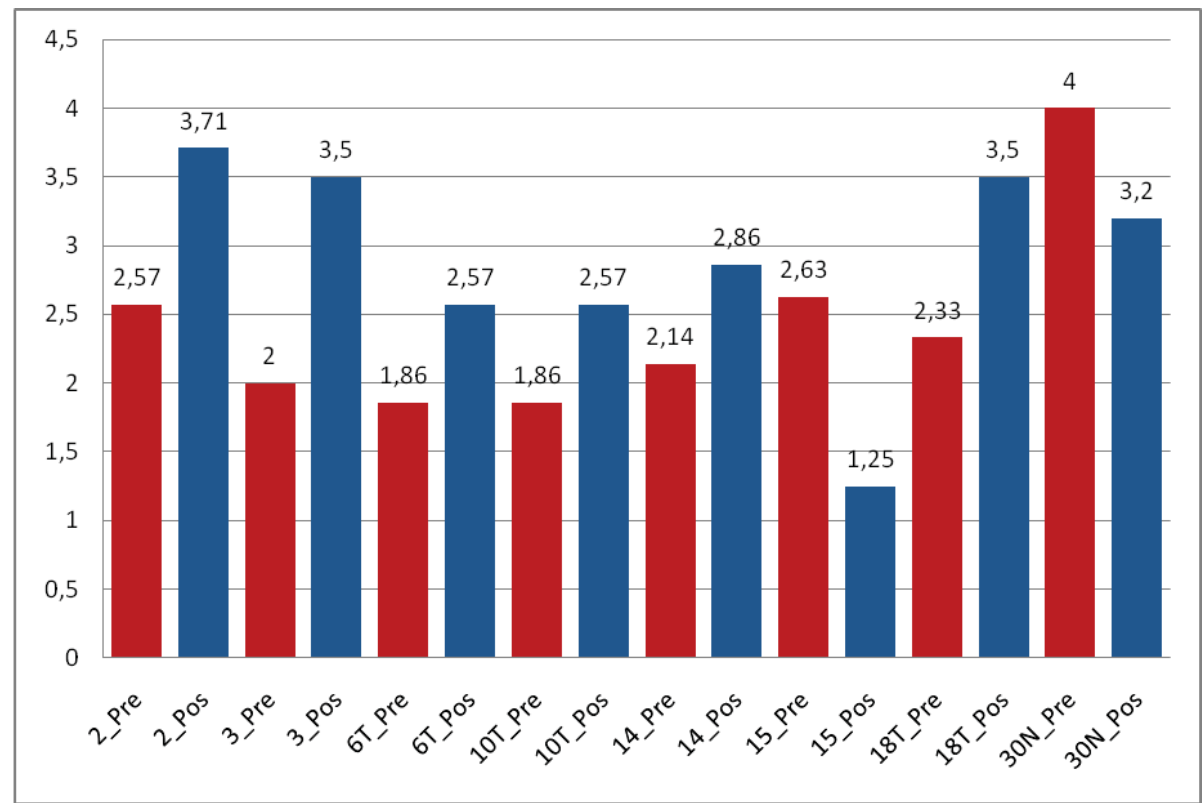

Gráfico 4.4 Média das questões do Grupo 1 com diferenças significativas

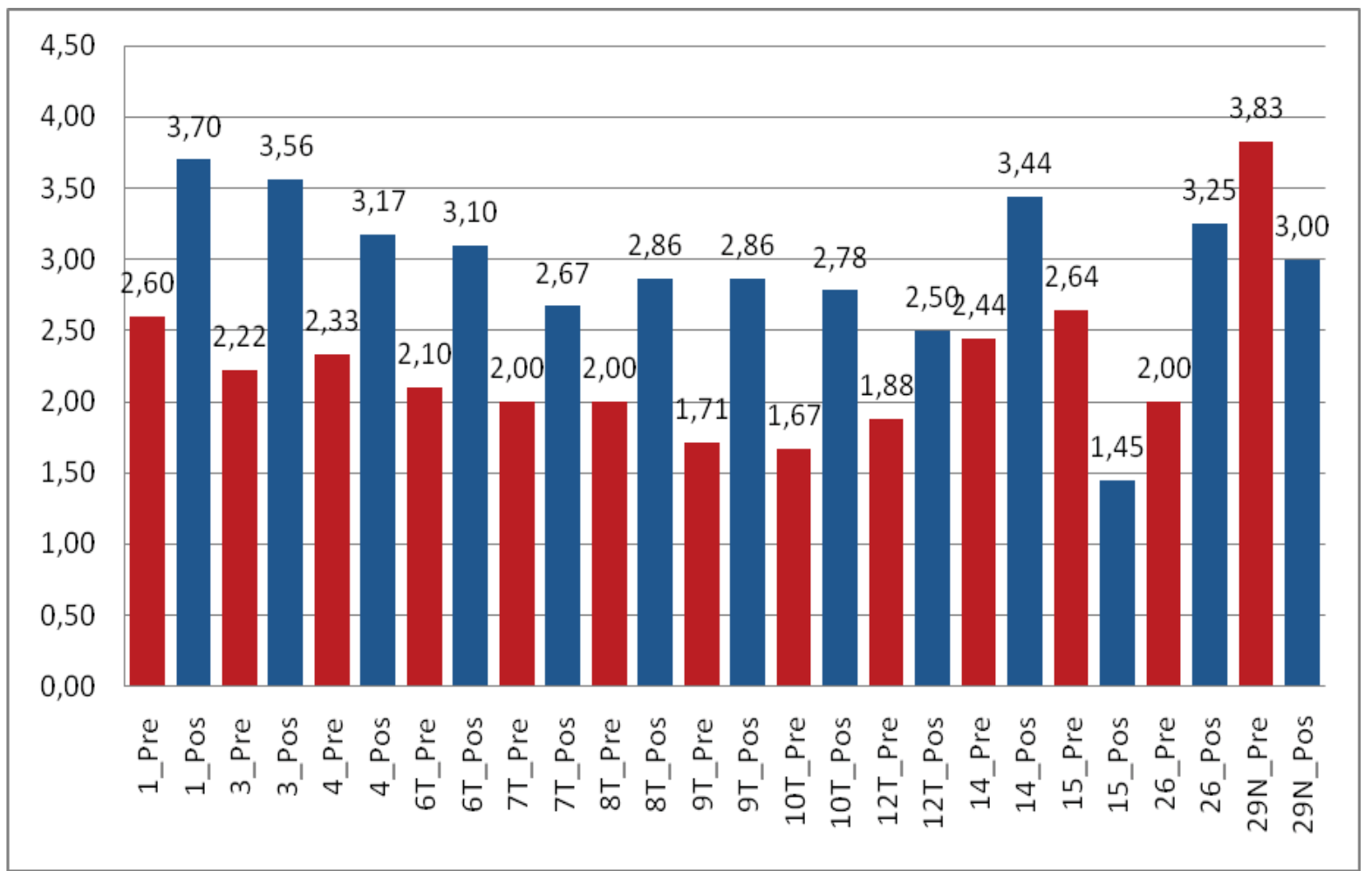

Gráfico 4.5 Média das questões do Grupo 2 com diferenças significativas 
$\mathrm{Na}$ análise com amostras independentes, observamos que os dois grupos se comportaram de forma equivalente nas etapas do quase-experimento. Essa equivalência pode ser justificada pela combinação social implícita que existe no site Delicious, utilizado tanto pelo grupo controle quanto pelo experimental. Além disso, outros fatores podem ter influenciado como a quantidade de participantes, o período curto para execução da tarefa, o nível de conhecimento dos participantes e outros fatores não identificados. Notamos que o nível de conhecimento inicial avaliado era básico ou nenhum sobre o assunto proposto para os dois grupos. Para esse caso a Internet oferece várias oportunidades de aprendizado, poderíamos, fazer outra suposição: será que em níveis de conhecimentos mais especificos, a combinação social apresentaria resultados mais satisfatórios com relação à aquisição do conhecimento? Essa situação pode ser examinada através das questões "5" e "9T" que apresentaram um ganho significativo no grupo experimental em relação ao controle.

Constatamos que o p-value $>\alpha=0,05$ para maioria das questões, exceto para as questões " 5 " com p_value $=$ 0,11 e "9T" com p_value $=0,07$. Sendo assim, não podemos rejeitar a hipótese nula, que aponta para igualdade das médias para a maioria das questões, exceto para as questões mencionadas anteriormente (" 5 " e "9T"). Concluímos que os grupos 1 e 2 (controle e experimental, respectivamente) possuem conhecimentos equivalentes sobre o assunto e as diferenças encontradas na média não foram significativas para quase todas as questões. Se considerarmos, contudo, as questões " 5 " e "9T", podemos afirmar que os grupos não são equivalentes quanto a essa particularidade do assunto, pois o grupo 2 (experimental) mostrou conhecer mais do que o grupo 1 (controle) com relação a essas duas questões, como mostra o Gráfico 3.6.

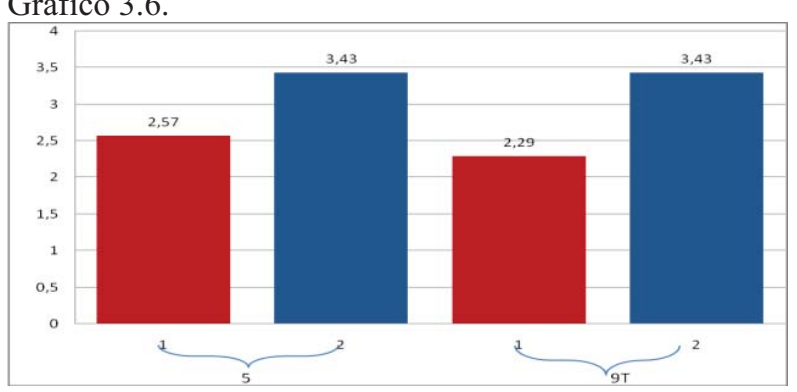

Gráfico 4.6 - Médias dos Grupos Experimental e Controle em relação às questões 5 e $9 \mathrm{~T}$

A hipótese H2 sobre a aquisição do conhecimento facilitada pela combinação social não é totalmente inviável. Notamos que para algumas particularidades sobre o assunto, a combinação social pode contribuir muito, tornando a hipótese $\mathrm{H} 2$ viável.
Esses resultados, bem como, os pré e pós testes, questionários e entrevistas estão detalhados na dissertação de mestrado que embasou esse trabalho de Silva, S.P.S.[19]

\section{Trabalhos Relacionados}

Nesta seção, são apresentados alguns trabalhos relacionados com o Modelo Oraculous.

- Um breve resumo do Modelo Ponderado de Relevância (WReL), segundo [10], é apresentado a seguir a partir da Equação 4.

$$
\begin{gathered}
\operatorname{Relevance}\left(p_{j}, q_{i}\right)=\frac{H_{i j}}{\sum_{\forall j} H_{i j}} \\
\operatorname{Sim}\left(q, q^{\prime}\right)=\frac{\left|q \cap q^{\prime}\right|}{\left|q \cup q^{\prime}\right|} \\
\operatorname{WRel}\left(p_{j}, q_{T}, q_{1}, \ldots, q_{n}\right)= \\
\frac{\sum_{i=1 \ldots . . n} \operatorname{Relevance}\left(p_{j}, q_{i}\right) \bullet \operatorname{Sim}\left(q_{T}, q_{i}\right)}{\sum_{i=1 . . . n} \operatorname{Exist}\left(p_{j}, q_{i}\right) \bullet \operatorname{Sim}\left(q_{T}, q_{i}\right)}
\end{gathered}
$$

No modelo de relevância é avaliado a relevância de uma página $p_{j}$ em relação a uma consulta $q_{i}$ no passado. A ideia é armazenar as experiências anteriores e a partir dessas experiências, observar o que é mais relevante para promover uma determinada página. A matriz $\mathrm{H}$ apresentada na Tabela 4 é um exemplo de como é armazenada a frequência de acesso de cada página $p_{j}$ relacionado a determinado termo $q_{i}$.

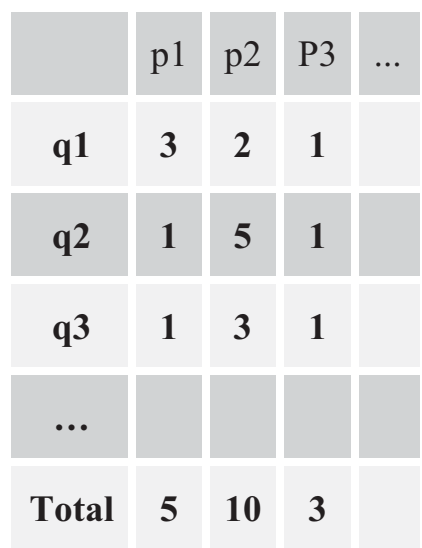

Tabela 4 - Exemplo da Matriz H 
Relevância (página, consulta) $(p 1, q 1)=3 / 5=0,60$

No modelo (WRel), o termo "Exists" é utilizado para avaliar se aquela página $p_{j}$ foi encontrada a partir do termo da consulta $q_{i}$, caso isso não tenha ocorrido, a similaridade entre $q_{i}$ e $p_{j}$ é desconsiderada.

Destacam-se também como trabalhos relacionados: o TeamWork [17] por ser um Sistema de Recomendação que auxilia na formação de equipes de trabalho; o ActivUFRJ [18], por estar vinculado a uma comunidade acadêmica em que um dos maiores objetivos é encontrar pesquisadores, especialistas ou pares com interesses em determinada área do saber; o ReCoP [18] como modelo de reputação para comunidades de práticas; o Sistema de Descoberta de Tags [12], implementado em redes sociais, como o Delicious, para descobrir através das Tags os interesses dos indivíduos. Além de um estudo de simulações em sistemas de recomendação híbridos baseado em conteúdo e por filtragem colaborativa, voltados para $e$ learning [13].

\section{Conclusões}

Procurou-se verificar em sites sociais as estratégias utilizadas com mecanismos de combinação social. Constatou-se que a solução adotada por esses sites ainda é um assunto pouco explorado. Essa constatação foi a principal motivação para o desenvolvimento dessa pesquisa.

Propomos um modelo de combinação social a ser implementado em um ambiente computacional, para isso foi desenvolvida uma ferramenta chamada Oraculous. O modelo proposto contribui para melhorar o aumento da rede de amigos e aquisição do conhecimento, hipóteses $\mathrm{H} 1$ e H2, respectivamente. Com relação a H2, aquisição do conhecimento, vale ressaltar que é necessário realizar outros experimentos como trabalhos futuros, para levantar mais indícios de sua viabilidade, pois as conclusões que se obteve no escopo desta pesquisa não foram satisfatórias.

Procurou-se explicitar características voltadas para auxiliar os próprios usuários a agregarem novos pares, de acordo com um determinado interesse, visando incentivar a aquisição do conhecimento através da observação dos outros. Para avaliar a viabilidade da solução proposta primeiramente foi realizado um quasi-experimento com aplicação de um pré e pós-teste, além da execução de uma tarefa com um conjunto de pessoas. Os resultados obtidos foram importantes para uma primeira tentativa de validar as hipóteses que orientam essa pesquisa, apresen- tando dados consistentes de confiabilidade na rede de amigos e aquisição do conhecimento por observação através da combinação social.

\section{Referências}

[1] BANDURA, A.. Social cognitive theory . In: Vasta, R. (Ed.). Annals of child development. Greenwich: JAI Press, v.6. p. 1-60. Six theories of child development, 1989.

[2] CAMPBELL, D. T. ; STANLEY, J. C. Experimental and quasi-esperimental desgns for Research. Boston: Houghton Mifflin. 84 p., 1963.

[3] GOLDER, S. ; HUBERMAN, B. A. The structure of collaborative tagging systems. Disponível em: http://www.hpl.hp.com/research/idl/papers/tags/t ags.pdf. Acesso em: 26 dez. 2008.

[4] KELLY, G. A. A Theory of personality: the psychology of personal constructs. New York: W.W. Norton \& Company, 189 p. 1963

[5] MOREIRA, M. A. Teoria de aprendizagem São Paulo: $E D U, 1999$

[6] MOTTA, C. L. R. Um ambiente de recomendação e filtragem cooperativas para apoio a equipes de trabalho.. Tese (Doutorado em Ciências em Engenharia de Sistemas e Computação) - Programa de Pós-graduação de Engenharia, Universidade Federal do Rio de Janeiro, RJ, 226 p. 1999.

[7] SEGARAN, T. Programming collective intelligence: building smart web 2.0 applications. Sebastopol: O’Reilly Media, 2007

[8] TERVEEN, L. G., McDONALD, D. W. Social matching: a framework and research agenda. ACM Transactions on Computer-Human Interaction, New York, v. 12, n. 3, p. 401-434, Sep. 2005.

[9] VYGOTSKY, L. S. Pensamento e linguagem. Ridendo Castigal Mores. 2007. Disponível em: http:/www.scribd.com/doc/2969385/vygotskypensamento-e-linguagem. Acesso em: nov. 2008.

[10] BARRY S., EVELYN B., JILL F., PETER B., MAURICE C., and OIS' in Boydell. Exploiting query repetition and regularity in an adaptive community-based web search engine. User 
Model. User-Adapt. Interact.,14(5):383-423, 2004.

[11] RICCI, Francisco, ROLACH, Lior, SHAPIRA, Bracha and KANTOR, Paul B. - Recommender Systems Handbook, ISBN 978-0-387-85819-7, 2011.

[12] XIN Li, Lei Guo, and YIHONG Eric Zhao. Tagbased social interest discovery. In WWW'08: Proceeding of the 17th international conference on World Wide Web, pages 675-684, New York, NY, USA,. ACM. 2008.

[13] NADOLSKI, R.J., VAN de Berg, B., BERLANGA, A., Drachsler, H., HUMMEL, H., Koper, R., Sloep, P.: Simulating Light-Weight Personalised Recommender Systems in Learning Networks: A Case for PedagogyOriented and Rating-Based Hybrid Recommendation Strategies. Journal of Artificial Societies and Social Simulation (JASSS), 12(14) 2009.

[14] COOPER, A.. About face 3: the essentials of interaction design. Indianapolis: Wiley Publishing, 2007

[15] FÜRST, P. GT9 - Processos cognitivos e linguisticos na educação matemática. Disponível em:

http://www.cp.ufmg.br/cpantigo/III SIPEM/18 set/9-Patricia.pdf. Acesso em: dez. 2008

[16] ROTTER, J.B. A New scale for the measurement of interpersonal trust. Journal of Personality, Farmington, . v. 35, n.4, p. 651-665, dec. 1967.

[17] MOTTA, C.L.R - Um Ambiente de Recomendação e Filtragem Cooperativas para Apoio a Equipes de Trabalho, Tese de DSc., COPPE/UFRJ, Rio de Janeiro, 1999.

[18] CRUZ, C.C.P.- ReCoP: Um Modelo de Sistemas de Reputação em Comunidades de Prática.. Dissertação (Mestrado em Informática) PPGI/UFRJ, 2008.

[19] SILVA, S.P.S - Oraculous: um modelo para combinação social em redes sociais - Dissertação (Mestrado em Informática) - PPGI/UFRJ Programa de Pós-Graduação do Instituto Técio Pacitti de Aplicações e Pesquisas Computacionais - Universidade Federal do Rio de Janeiro, Instituto de Matemática, Núcleo de Computação Eletrônica, Março de 2009. Disponível em http://www.nce.ufrj.br/ginape/publicacoes/disser $\underline{\text { ta- }}$

$\underline{\text { co- }}$ es/d_2009/d_2009_soraia_pacheco_de_almeida silva.pdf

[20] VOLKERS, C. B. - As Palavras do Oráculo Delphos: Um estudo sobre o De Pythiae Oraculis de Plutarco, Dissertação de Mestrado, UFMG, Belo Horizonte, 2007. Disponível em http://www.multiculturas.com/julianus/textos/CBy laardt Volker Plutarco Oraculo Pitia.pdf. Acesso em out. 2014

[21] IBOPE - Cresce o número de usuários ativos nas Redes Sociais, 2012

http://www.ibope.com.br/ptbr/noticias/Paginas/Cresce-o-numero-de-usuariosativos-nas-redes-sociais.aspx,

[22] IBOPE - Brasil está entre os dez países que mais acessam redes sociais, 2010 -

http://www.ibope.com.br/ptbr/noticias/Paginas/Brasil $\% 20$ est $\% \mathrm{C} 3 \% \mathrm{~A} 1 \% 20 \mathrm{e}$ ntre $\% 20 \mathrm{os} \% 20 \mathrm{dez} \% 20 \mathrm{pa} \% \mathrm{C} 3 \%$ ADses $\% 20$ que $\% 20$ mais $\% 20$ acessam $\% 20$ redes $\% 20$ sociais.aspx

[23] VYGOTSY, L.S. - A Formação Social da Mente $-4^{a}$ Edição. São Paulo: Martins Pontes 1991.

[24] FARIA, C. C. - Fatos Sociais - InfoEscola: Navegando e Aprendendo. Disponível em http://www.infoescola.com/sociologia/fatossociais/, Acesso em out. 2014.

[25] PEREIRA, R. ; SILVA, S. R. P. . The Use of Cognitive Authority for Information Retrieval in Folksonomy- Based Systems. In: ICWE Eighth International Conference on Web Engineering, 2008, Nova York. Eighth International Conference on Web Engineering, 2008. p. 325 331

[26] PEREIRA, R. ; SILVA, S. R. P. . Folksonomias: Uma Análise Crítica Focada na Interação e na Natureza da Técnica. In: IHC 2008 VIII Simpósio Sobre Fatores Humanos em Sistemas Computacionais, 2008, Porto Alegre. VIII Simpósio Brasileiro de Fatores Humanos em Sistemas Computacionais (IHC 2008), 2008. p. 126135 . 